\title{
The Role of the Innovation Ecosystem for Regional Cluster Development: The Case of the Lake Constance Region
}

\author{
Lars Schmitt \\ Technical University Munich, Germany \\ Sebastian Woelk \\ Fraunhofer Institute for Production Technology IPT Aachen, Germany \\ Wolfgang $\mathrm{H}$. Schulz \\ Zeppelin University Friedrichshafen, Germany
}

\begin{abstract}
The demands on companies, especially on their ability to innovate, have risen dramatically in recent years. Hence, the importance of partnerships, networks, clusters and ecosystems has increased. When aiming for innovation it is generally accepted that merging various skills may lead to competitive advantages. So-called innovation ecosystems would like to promote and accelerate this. In general, ecosystems are understood as a space in which various actors are located. Each actor behaves according to certain roles. Each role is associated with specific tasks. Little is known about the actors, roles and tasks within an innovation ecosystem. The objective of this paper was to illustrate these three aspects in one model. From various scientific theories, a model has been developed that can be used to describe innovation ecosystems. The developed model has been applied to a real innovation ecosystem, the Lake Constance region in Germany, and has been validated by a qualitative survey in the form of expert interviews. The key results are that innovation ecosystems can be visualized with the developed model and that the interviewed experts could identify themselves with the given roles and tasks. Moreover, additions to the model were proposed during the expert interviews. Based on that research, a new understanding of regional clusters is introduced with the aim of developing clusters into instruments for promoting innovation.
\end{abstract}

Keywords: innovation ecosystems, regional clusters, networks, inter-organizational collaboration, SMEs

JEL classification: O33, R1 1

\section{Introduction}

Since the mid-1990s, it has been a goal of European policy to create and promote an innovation culture, to design ideal framework conditions for innovation and to strengthen research and science. In the so-called Lisbon Strategy, which was defined by the European Council in Lisbon in 2000, there is said that 'the European Union (EU) should become the most competitive and dynamic knowledge-based economy in the world, capable of sustainable economic growth with more and better jobs and greater social cohesion.' The Lisbon Strategy involved an action and development plan, in which innovation plays a fundamental role to raise the economic growth in the EU. It was also stressed that there is a 'need for a broad and systematic approach to innovation' (Rossi, 2005). The current EU's funding program, 
called 'Horizon 2020', illustrates that this need still exists. Holistic approaches, such as the ecosystem approach, make an important contribution to this.

\section{Theoretical background}

The support of clusters is also mentioned in European strategies and policies. However, clusters already won the attention of scientists and practitioners before they have been on political agendas. The concept of clusters has been strongly influenced by Porter (1998), who describes clusters as agglomerations of interrelated companies and institutions. These actors usually belong to a particular or related industry. It is also important to emphasize the geographical proximity of the actors, which is characteristic of a cluster.

In addition, companies in clusters can be linked together in both the vertical and horizontal directions of value creation. Vertical here means that there are companies that operate along a common value chain and complement each other if necessary. Horizontal in this context describes companies that offer similar products or have similar skills and competencies. As a result, actors within a cluster can either cooperate or compete (Haag, 2003).

According to Porter, clusters play an important role when it comes to increasing the innovation capability of a company. Companies which are active in a cluster environment have a better sense for the market, and thus, for the customer. Through personal exchange and partial or large-scale cooperation, trends and new customer needs are identified at an early stage. As a result, a wide variety of actors is integrated into the innovation process of clusters (Porter, 1998).

In terms of fostering innovation, clusters are similar to the theoretical model of innovation ecosystems. In 1993, the term 'business ecosystem' was introduced into management literature by Moore. He describes a business ecosystem as an economic community, which is composed of organizations, and individuals who interact with each other. According to Moore (1996), producers, suppliers, competitors, investors, banks as well as state institutions and customers belong to a business ecosystem. Adner (2006) sums up the goal of ecosystems as follows: "When they work, ecosystems allow firms to create value that no single firm could have created alone.' He coined the term of the so-called innovation ecosystem. According to Adner (2012), an innovation ecosystem aims to create and promote innovations, which should finally be brought to the market. He notes that the success of an innovation no longer depends solely on one actor but further on critical partners. In his opinion, these critical partners are the reason why even great innovations might fail.

Ecosystems can also be described as more open than clusters, if we refer to the open innovation approach by Chesbrough (2003). The reason for this is the industry focus of regional clusters. Chesbrough (2003) claims that companies should include and use both internal and external ideas in order to increase their innovation potential. This should lead to competitive advantages.

In their scientific work 'Collaborate to innovate', Kastalli et al. (2013) deal with socalled city ecosystems. They argue that it is necessary to coordinate different components, like education, trade, entrepreneurship, administration and infrastructure to create a functioning city ecosystem. Hence, urban ecosystems are extremely complex entities, which in turn make them comparable to business or innovation ecosystems.

The scientists examined several cities in order to deconstruct the prevailing ecosystem. By deconstructing different city ecosystems, Kastalli et al. (2013) identified various actors and roles, which can be found in every ecosystem as well as 
in clusters. They divide the actors into the following five categories: Government \& Utilities, Academia, Businesses, Entrepreneurs and Intermediators. In addition, they propose the following roles: Talent \& Knowledge (e.g. universities, colleges), Capital (e.g. banks, VC companies), Scales (e.g. large companies), Niches (e.g. SMEs), Innovators (e.g. start-ups, entrepreneurs), Infrastructure (e.g. traffic and transportation systems), Facilitators (e.g. Incubators), Representatives (e.g. mediators), Promoters (e.g. governmental funding agencies), Connectors \& Integrators (e.g. networks), Hub (e.g. state government) and Influencers (e.g. European Union, federal government). Kastalli et al. (2013) illustrate a city ecosystem with its existing actors that exercise one or more roles within the system. This is a valuable basis for the development of the model.

The same applies to Sölvell et al. (2003), who identify five key players within a regional cluster: companies, the state or the government, financial institutions, educational or research institutions and so-called institutions for collaborations. The mentioned institutions for collaborations can be described as a focal organization, which is dedicated to coordinate actors and their resources.

\section{Methodology}

In the following, the data resources of the qualitative survey are described in more detail and further theories and models are presented, in the course of the model development. Afterwards, the results are presented and discussed. This is followed by a conclusion and an outlook on further research.

\section{Data sources}

The survey consisted of guided interviews with experts. As the research object represented the Lake Constance region, we identified many relevant actors for our study. From these, we found five actors, which were willing to participate in our survey and to provide a representative, who can be interviewed. The representatives were as follows: a representative from a company from the real economy (Institution 1), one from the corporate incubator or start-up hub of this company (Institution 2), one from a state institution for regional economic development (Institution 3), one from the regional chamber of commerce (Institution 4) and one from a university (Institution 5).

A conversation guide was used to conduct the expert interviews, which contained openly formulated questions that helped to obtain specific statements about a particular issue. The respondent could freely answer the questions. In addition, stimuli in the form of pictures, charts etc. were used. Each interview took between 45 and 60 minutes. The interviews were recorded and then transcribed, coded and evaluated according to Mayring (2010).

\section{Model development}

Based on Sölvell et al. (2003), in a first step, we distinguish between five types of actors that are essential for an innovation ecosystem. These are the already mentioned actors: companies from the real economy, companies from the financial economy, educational and research institutions, the state or the government and focal organizations (Table 1). 
Table 1

Actors within an Innovation Ecosystem

\begin{tabular}{ll}
\hline Types of actors & Examples \\
\hline Companies from the real economy & Producers, service providers \\
Companies from the financial economy & Banks, VC companies, business angels \\
Educational and research institutions & $\begin{array}{l}\text { Universities, non-university research } \\
\text { institutions }\end{array}$ \\
State/Government & $\begin{array}{l}\text { Ministries, economic development } \\
\text { programs, infrastructure projects }\end{array}$ \\
Focal organizations & Cluster organizations, associations, \\
chambers, clubs, networks
\end{tabular}

Source: Author's illustration based on Sölvell et al. (2003)

In the second step, we describe necessary components of an innovation, defined by Schuh et al. (2017):

- First, it requires an idea, which is the starting point of an innovation process according to Birkinshaw et al. (2007). Schumpeter (1934) states that it requires both the inventor's idea and the entrepreneur's practical implementation to create an innovation. Furthermore, he claims that innovations can be achieved by recombining existing ideas. This is primarily reflected in the open innovation approach by Chesbrough (2003) or the cross-industry innovation approach by Gassmann et al. (2010).

- Knowledge plays a significant role in the innovation process, too. It is a prerequisite for every creative process and it enables the implementation of an idea. According to Nonaka et al. (1996), a knowledge base can be created via knowledge transfer. In his opinion, networks promote and stimulate the building of such a knowledge base.

- Capital is another key factor for the promotion of innovations (Valkokari, 2015). Especially in the early stages of innovative projects, a lot of capital is needed. In this phase, little or no returns are usually achieved. It is also unclear if a possible investment will lead to success, which is why venture capital is of importance especially at the beginning and later in the growth phase (Chandler, 2015).

- For a network-based innovation, means of production are necessary. This includes material resources, such as machinery or laboratory equipment. They serve to realize a marketable innovation (Van Lancker et al., 2016)

- Collaborations aim to bring a product or service to the market. It is therefore very important to solicit feedback from the market. Information about the needs and requirements of the customer as well as the competitors and their competing products can be collected (Wittenberg, 2006).

- Due to the large number of actors, who bring their respective resources into the innovation process, it is necessary to have an entity, which is responsible for organization (Glückler et al., 2012). 
Figure 1

Components of an Innovation with the Associated Roles and Tasks

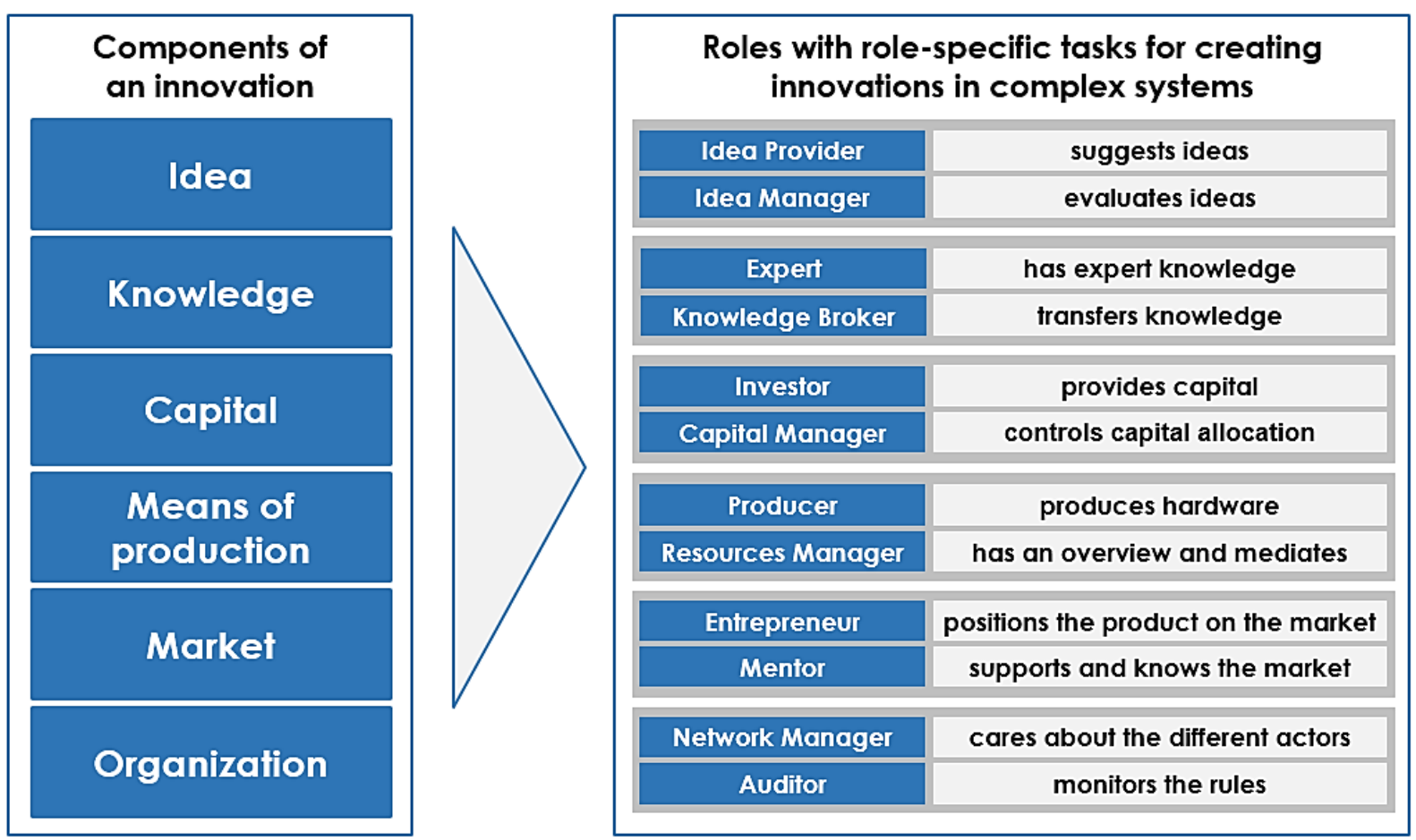

Source: Author's illustration based on Schuh et al. (2017)

The mentioned components of an innovation can be used to derive certain roles and tasks that exist within an innovation ecosystem (Figure 1).

In a third step, these roles and tasks are developed using existing role definitions from the literature. It is important to note that the following roles can be performed either by an institution or by a single person.

- The idea provider gives ideas and suggests new products, services or processes. Furthermore, this institution or person interacts with actors outside the company (based on 'Inventor' - Schumpeter, 1947 and 'Co-Creator' Leminen, 2015).

- The idea manager combines generated ideas by integrating heterogeneous knowledge in order to develop and assess them (based on 'Integrator' Leminen, 2015).

- The expert participates in the innovation process by providing intangible resources (e.g. know-how). As a result, this institution or person contributes significantly to the development of the new product, service or process (based on 'Contributor' - Leminen, 2015).

- The knowledge broker gathers possible product or service ideas, which have been collected from various sources. Then, this institution or person distributes this information to the network or to external partners (based on 'Messenger' Leminen, 2015).

- The investor has the task of providing financial resources, which flow into R\&D activities as well as into the market launch of the innovation (Sölvell, 2009).

- The capital manager allocates the capital provided by the investor and thus manages its distribution. This institution or person recognizes financial needs and ideally covers them (based on 'Accountant' - Wenger, 1998). 
- The producer manufactures the innovation by using resources and means of production. Thus, production factors such as labor, technologies and materials are combined (based on 'Producer' - Leminen, 2015 and 'Manufacturer' Redlich, 2011).

- The resources manager supports the actors in using their existing resources in an optimal and targeted way. This institution or person navigates the resources in the appropriate direction and mediates between the actors (based on 'Facilitator' - Leminen, 2015).

- The entrepreneur is dedicated to bring the innovation to the market by designing and realizing a suitable business model to reach the customer (based on 'Accessory Planner' - Leminen, 2015 and 'Entrepreneur' Schumpeter, 1947).

- The mentor influences decision-making processes by performing an advisory role, which is attributed to the institution or the person because of its, his or her expertise (based on 'Instigator' - Leminen, 2015).

- The network manager coordinates the actors within the network and thus acts as a focal organization. This institution or person collects information about their needs, requirements and wishes and tries to bring them in line with other actor's objectives. In addition, the network manager organizes and promotes any form of collaboration between various parties (based on 'Coordinator' Leminen, 2015.)

- The auditor is responsible for the more complex or holistic objectives of the network and serves as a supervisory board. This institution or person monitors the achievement of the goals and takes care of the compliance (based on 'Hub' - Kastalli et al. (2013).

In the fourth step, we introduce the institutional role model (IRM) by Schulz et al. (2016). The institutional role model is an instrument that helps to describe the roletakeover of actors in a complex system, like in an ecosystem or a cluster. In the socalled IRM-matrix, the actors of an ecosystem can be listed. The different actors undergo an evaluation process. This process can contain several perspectives up to a $360^{\circ}$-rating, in which all actors evaluate each other. In our case, the five representatives of our survey preferred to rate themselves regarding the role perception of their institution. The scaling of the intensity of the role perception runs from 1 to 5:

1 - The role should not be taken over by the actor.

2 - The role could be assumed by the actor, but he/she has no experience in the perception of this role.

3 - The role could be taken by the actor, but he/she has little experience in exercising that role.

4 - The actor should take on the role because he/she has solid experience in performing this role.

5 - The actor should take on the role because he/she has a unique selling point in the perception of this role.

The following IRM-matrix (Figure 2) represents the developed model by bringing together the different types of actors (Table 1), the components of an innovation and the defined roles (Figure 1). On the Y-axis, the different roles are plotted, categorized according to the components for an innovation. On the X-axis, the actors can be found, assigned to their respective type of actor.

The numerical evaluation is a result of the expert interviews and represents the role perception of each representative. Based on the figures, a statement can be made about the innovative capability of the ecosystem. 
Figure 2

IRM-matrix and Evaluation of the Interview Partners

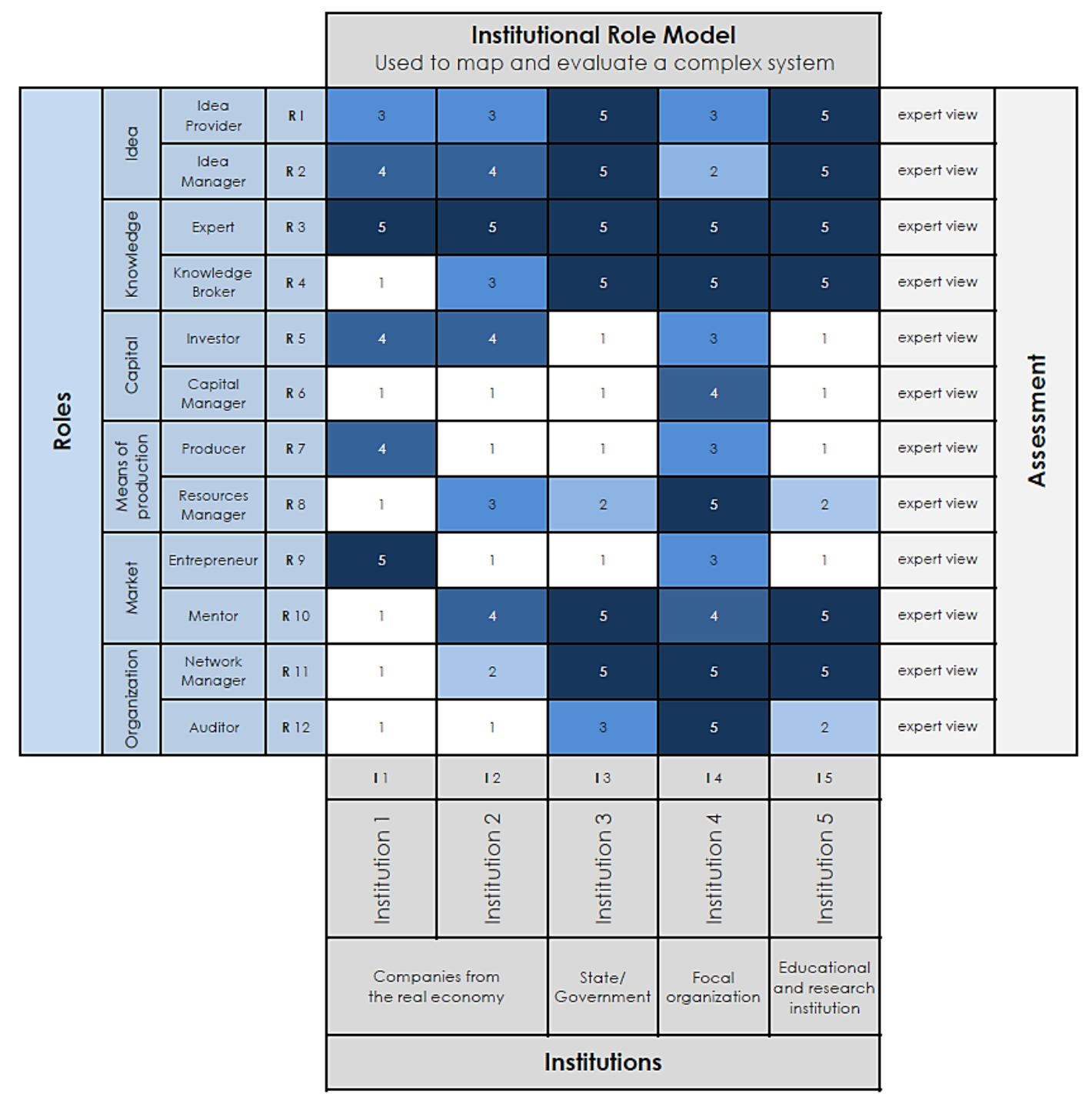

Source: Author's illustration based on Schulz et al. (2016)

\section{Results}

In this study, the developed model has been tested and verified with five actors from the Lake Constance region. Based on the representatives' statements, it can be said that the ecosystem approach is considered as relevant. In practice, this is due to the importance of cooperation, networks and clusters. It seems that there is a certain discrepancy between theory and practice, as most of the representatives refer to the ecosystem approach as relevant, but most of them are not aware of using the approach in practice. The reason may be that the importance of theoretical models is considered to be low in practice, or because there is a lack of knowledge of theoretical models in general.

Regarding the types of actors (Table 1), the representatives proposed to add the end-user or customer to the model, which makes sense from the perspective of useroriented product development. Moreover, non-governmental organizations and standardization organizations or committees were mentioned as complementary points. In the context of the components for innovation (Figure 1), the experts came up with the aspect of culture. Culture here means the existing business, company 
and network culture. According to the representatives, this aspect should be included in the model. In consideration of the fact that the roles and tasks are derived from the components, an increasing number of components lead to further roles and tasks.

When evaluating their own role perception, the representatives tended to record the target state, even though it was about the actual state. Overall, this form of reflection was received very positively by the representatives. One aspect that has been mentioned besides the research focus is the legal framework of innovations, which is generally perceived as an obstacle.

When it comes to the limitations of this study, it has to be stated that the choice of actors has been arbitrary. In practice, it is advisable to focus on a single actor and to form the respective ecosystem around this actor. After the successful presentation of such an ecosystem, it can be analysed according to certain aspects, from which recommendations for the respective actor can be derived. In some cases, it is also difficult to distinguish between the different types of actors because it comes to overlaps. A governmental organization can for example act as a focal organization and can therefore be assigned to the type 'state/ government' as well as to 'focal organization'. Furthermore, there may be other types of actors and components for an innovation and further roles or tasks that were not identified in this research.

\section{Conclusion}

The developed model consists of three concepts or theories. In a first step, these were the types of actors identified with reference to Sölvell et al. (2003) for an innovation ecosystem. The five mentioned types of actors - companies from the real economy, companies from the financial economy, educational and research institutions, the state or the government and focal organizations - should be supplemented by other types of actors according to the results of the qualitative survey.

The second step involved the components for an innovation - ideas, knowledge, capital, means of production, market, organization - according to Schuh et al. (2017), from which various roles and tasks were derived in the third step. The surveyed representatives had again suggestions to complete the model.

In the fourth step, the types of actors as well as the components and roles were transferred to the matrix of the institutional role model according to Schulz et al. (2016). This step resulted in the desired description model, which is generally a criteria and evaluation system for the optimal definition of a cooperative division of labor in a complex system. Therefore, ecosystems, clusters and networks can be evaluated and developed based on the proposed model.

The model was tested and validated with five actors from the Lake Constance region. Representatives of these actors were interviewed as experts. The survey of these experts and in particular their assessment of their own role perception showed that there was a high level of identification with the roles.

In this paper, we also wanted to point out those innovation ecosystems and regional clusters are equally complex systems. In order to gain a deeper understanding of such systems, they must be simplified and deconstructed. Since clusters have been around for decades, it is important to introduce state of the art research findings into this field, in particular from the innovation and start-up context. Our model contributes to this by describing the actors, their roles and tasks of an innovation ecosystem, that are necessary to create and promote innovation. These findings can be transferred to clusters. 
What different complex systems have in common and how innovations can be specifically promoted within them is an important aspect for future research. Moreover, the components for an innovation as well as the roles and tasks should be described in more detail, as they require a broader scientific basis. The expert interviews provided additional impulses that could not be dealt with in the context of this study. Especially the aspect of culture should be deepened.

\section{References}

1. Adner, R. (2006), "Match Your Innovation Strategy to Your Innovation Ecosystem", Harvard Business Review, Vol. 84, No. 4, pp. 98.

2. Adner, R. (2012), The Wide Lens. What Successful Innovators See That Others Miss, Penguin, New York.

3. Birkinshaw, J., Hansen, M. T. (2007), "The Innovation Value Chain", Harvard Business Review, Vol. 85, No. 6, pp. 121-130.

4. Chandler, A. D. (2015), "The Global Startup Ecosystem Report 2015", available at https://startup-ecosystem.compass.co/ser2015/ (03 February 2018)

5. Chesbrough, H. (2003), Open Innovation: The New Imperative for Creating and Profiting From Technology, Harvard Business Press, Boston.

6. Gassmann, O., Enkel, E. (2010). "Creative imitation. Exploring the case of cross-industry innovation", R\&D Management, Vol. 40, No. 3, pp. 256-270.

7. Glückler, J., Dehning, W., Janneck, M. (2012), Unternehmensnetzwerke: Architekturen, Strukturen und Strategien, Springer-Verlag, Berlin.

8. Kastalli, I. V., Neely, A. (2013), Collaborate to Innovate: How Business Ecosystems Unleash Business Value, University of Cambridge.

9. Leminen, S. (2015), Living Labs as Open Innovation Networks - Networks, Roles and Innovation Outcomes, Aalto University, Helsinki,

10. Mayring, P. (2010), "Qualitative Inhaltsanalyse. Grundlagen und Techniken", in Mey, G., Mruck, K. (Ed.), Handbuch qualitative Forschung in der Psychologie, VS Verlag für Sozialwissenschaften, Weinheim, pp. 601-613.

11. Moore, J. F. (1993), "Predators and Prey - A New Ecology of Competition", Harvard Business Review, Vol. 71, No. 3, pp. 75-86.

12. Moore, J. F. (1996), The Death of Competition: Leadership and Strategy in the Age of Business Ecosystems, HarperBusiness, New York.

13. Nonaka, I., Umemoto, K., Senoo, D. (1996), "From Information Processing to Knowledge Creation: A Paradigm Shift in Business Management", Technology in society, Vol. 18, No. 2, pp. 203-218.

14. Porter, M. E. (1998), "Clusters and the New Economics of Competition", Boston: Harvard Business Review, Vol. 76, No. 6, pp. 77-90.

15. Redlich, T. (2011), Wertschöpfung in der Bottom-up-Ökonomie, Springer-Verlag, Heidelberg.

16. Rossi, F. (2005), "Innovation policy in the European Union: instruments and objectives", working paper 2009, Universita' di Modena e Reggio Emilia, 06 March 2007

17. Schuh, G., Woelk, S. (2017), "Design framework of an ecosystem for network-based innovation: Conceptual Research Methodology", in Management of Engineering and Technology (PICMET), 2017 Portland International Conference, pp. 1-11.

18. Schulz, W. H., Wieker, H. (2016), "Co-operative Intelligent Transport Systems: Neve Marktchancen durch den Systemverbund aus Automobil- und Telekommunikationsindustrie", in Future Telco III: Powerplay für Telekommunikationsunternehmen, pp. 138150.

19. Schumpeter, J. A. (1934), The Theory of Economic Development, Transaction Publishers.

20. Schumpeter, J. A. (1947), "The Creative Response in Economic History", The Journal of Economic History, Vol. 7, No. 2, pp. 149-159.

21. Sölvell, Ö., Lindqvist, G., Ketels, C. H. M. (2003), "The Cluster Initiative Greenbook", Ivory Tower Publishing, Stockholm. 
22. Sölvell, Ö. (2009), "Clusters. Balancing Evolutionary and Constructive Forces.", Ivory Tower Publishing, Stockholm.

23. Valkokari, K. (2015), "Business, Innovation, and Knowledge Ecosystems: How They Differ and How to Survive and Thrive within Them", Technology Innovation Management Review, Vol. 5, No. 2, pp. 17-24.

24. Van Lancker, J., Mondelaers, K., Wauters, E., van Huylenbroeck, G. (2016), "The Organizational Innovation System: A systemic framework for radical innovation at the organizational level", Technovation, Vol. 52, pp.40-50.

\section{About the authors}

Lars Schmitt is a PhD student at the Technical University Munich (GER) at the Chair of Innovation Economics. He is a graduate of the master in General Management of the Zeppelin University Friedrichshafen (GER). The author can be contacted via lars.schmitt@tum.de.

Sebastian Woelk is a PhD candidate at the Fraunhofer Institute for Production Technology IPT Aachen (GER) and has been intensively involved in innovation ecosystems and technology transfer. The author can be contacted via sebastian.woelk@yahoo.de.

Wolfgang H. Schulz is the owner of the Chair of Trade, Logistics and Mobility at the Zeppelin University Friedrichshafen. The authors can be contacted via wolfgang.schulz@zu.de. 